\title{
Amyloid $\beta$ Protein Modulates Glutamate-Mediated Neurotransmission in the Rat Basal Forebrain: Involvement of Presynaptic Neuronal Nicotinic Acetylcholine and Metabotropic Glutamate Receptors
}

\author{
James H. Chin, Li Ma, David MacTavish, and Jack H. Jhamandas \\ Department of Medicine (Neurology) and Center for Neuroscience, University of Alberta, Edmonton, Alberta, Canada T6G 2S2
}

Amyloid $\beta(\mathrm{A} \beta)$ protein, a 39-43 amino acid peptide deposited in brains of individuals with Alzheimer's disease (AD), has been shown to interact directly with a number of receptor targets including neuronal nicotinic acetylcholine receptors (nAChRs) and glutamate receptors. In this study, we investigated the synaptic effects of $A \beta_{1-42}$ on glutamate-mediated neurotransmission in the diagonal band of Broca (DBB), a cholinergic basal forebrain nucleus. Glutamatergic miniature EPSCs (mEPSCs) were recorded using whole-cell patchclamp recordings from identified cholinergic DBB neurons in rat forebrain slices. In $54 \%$ of DBB neurons, bath application of A $\beta_{1-42}(100$ $\mathrm{nM})$, but not $\mathrm{A} \beta_{42-1}$ (inverse fragment), significantly increased the frequency of mEPSCs without affecting amplitude or kinetic parameters (rise or decay time). In $32 \%$ of DBB neurons, bath application of $\mathrm{A} \beta_{1-42}$ significantly decreased only the frequency but not amplitude of mEPSCs. Application of dihydro- $\beta$-erythroidine ( $\mathrm{DH} \beta \mathrm{E}$ ) (an antagonist for the $\alpha 4 \beta 2$ subtype of nAChRs) but not $\alpha$-bungarotoxin (an antagonist for the $\alpha 7$ subtype of nAChRs) blocked $\mathrm{A} \beta_{1-42}$-mediated increases in mEPSC frequency. The $\mathrm{A} \beta_{1-42}$-mediated increase in glutamatergic transmission is thus presynaptic and mediated via non- $\alpha 7 \mathrm{AChRs}$. In contrast, $\mathrm{A} \beta_{1-42}$-mediated decreases in mEPSC frequency could not be antagonized by either $\mathrm{DH} \beta \mathrm{E}$ or $\alpha$-bungarotoxin. However, the $\mathrm{A} \beta_{1-42}$-evoked depression in mEPSC frequency was antagonized by $(R S)$ - $\alpha$-methyl-4-carboxyphenyglycine, a nonselective group I/II metabotropic glutamate receptor antagonist. These observations provide further insight into the mechanisms whereby $\mathrm{A} \beta$ affects synaptic function in the brain and may be relevant in the context of synaptic failure observed in AD.

Key words: amyloid; cholinergic; nicotine; patch clamp; brain slice; miniature EPSCs

\section{Introduction}

Alzheimer's disease (AD), a condition that afflicts the elderly, is characterized by a progressive decline in memory and other cognitive functions such as language and perception (McKhann et al., 1984). Key neuropathological findings in individuals with AD include a selective loss of acetylcholine-synthesizing (cholinergic) neurons of the basal forebrain and the presence of extracellular and intracellular plaques composed of amyloid $\beta(\mathrm{A} \beta)$ protein (Whitehouse et al., 1982). The loss of cholinergic neurons has been linked to memory and cognitive impairment seen in AD (Price, 1986). The diagonal band of Broca (DBB), a cholinergic basal forebrain nucleus, is one of the major sources of cholinergic innervation to the hippocampus and cerebral cortex in rats and humans (Mesulam et al., 1983). Within the DBB, immunohisto-

\footnotetext{
Received Dec. 19, 2006; revised June 4, 2007; accepted June 26, 2007.

This work was supported by the Canadian Institutes of Health Research (CIHR). J.H.C. was supported by studentship awards from the Natural Sciences and Engineering Research Council (Canada) and the CIHR, and J.H.J. is the recipient of a Canada Research Chair in Alzheimer Research.

Correspondence should be addressed to Dr. Jack H. Jhamandas, Department of Medicine (Neurology), University of Alberta, 530 Heritage Medical Research Center, Edmonton, Alberta, Canada T6G 2S2. E-mail: jack.jhamandas@ualberta.ca.

D0I:10.1523/JNEUROSCI.1843-07.2007

Copyright $\odot 2007$ Society for Neuroscience $\quad$ 0270-6474/07/279262-08\$15.00/0
}

chemical methods for detecting choline acetyltransferase reveal that between 34 and $45 \%$ of neurons are cholinergic (Eckenstein and Sofroniew, 1983).

$\mathrm{A} \beta$, a 39-43 amino acid peptide, is a critical pathological mediator of the synaptic dysfunction, synaptic loss, and neuronal death observed in AD (Small et al., 2001; Selkoe, 2002). Before the development of $\mathrm{A} \beta$ plaques, deficits in basal synaptic transmission and long-term potentiation (LTP), a form a synaptic plasticity, have been observed in transgenic mice that overexpress $\mathrm{A} \beta$ (Larson et al., 1999; Moechars et al., 1999). Furthermore, in vitro and also in vivo experiments have shown that soluble oligomers of A $\beta$ are capable of inhibiting LTP (Lambert et al., 1998; Walsh et al., 2002). Together, these data demonstrate the importance of soluble forms of $\mathrm{A} \beta$ in mediating synaptic dysfunction and correlate with neuropathological observations in brains of patients with mild cognitive impairment and $\mathrm{AD}$, where synaptic disruption and loss are early pathological features (Davies et al., 1987; Hamos et al., 1989; Masliah et al., 1991). However, there is presently little information on how $\mathrm{A} \beta$ may influence normal synaptic transmission in the brain, particularly in structures such as the cholinergic basal forebrain that are at the epicenter of the chemical pathology seen in AD.

Currently, no receptor has been definitively identified to me- 
diate $A \beta$ actions on synaptic function, although several target receptors have been proposed. However, binding studies using postmortem human brain tissue and $\alpha 7 \mathrm{SK}-\mathrm{N}-\mathrm{MC}$ cell membranes indicate that $\mathrm{A} \beta$ shows a high affinity for neuronal nicotinic acetylcholine receptors (nAChRs) (Wang et al., 2000a,b). Furthermore, electrophysiological studies in Xenopus oocytes (Dineley et al., 2002) and rat neurons (Pettit et al., 2001; Fu and Jhamandas, 2003) demonstrate that effects of $A \beta$ are expressed through a variety of subtypes of nAChRs. Although there are very few examples of primary nicotinic-mediated excitatory synaptic transmission in the CNS (Phelan and Gallagher, 1992; Zhang et al., 1993; Frazier et al., 1998), nAChRs have been demonstrated to be involved as neuromodulators of glutamate-mediated excitatory synaptic transmission (Vidal and Changeux, 1993; McGehee et al., 1995; Alkondon et al., 1996; Radcliffe and Dani, 1998; Lambe et al., 2003). In addition to nAChRs, metabotropic glutamate receptors (mGluRs) have also been shown to modulate glutamatergic neurotransmission in the DBB and other brain regions (Easaw and Jhamandas, 1994; Anwyl, 1999). However, the nature of interactions of $\mathrm{A} \beta$ with mGluRs are primarily unknown. In this study, we examined whether the effects of $A \beta_{1-42}$ on glutamate-mediated EPSCs in the cholinergic rat basal forebrain nucleus, DBB, are mediated by specific subtypes of nAChRs or mGluRs.

\section{Materials and Methods}

Cy3-192 IgG neuronal labeling. The majority of neurons used in this study (55 of 62) were identified with Cy3-192 IgG (Advanced Targeting Systems, San Diego, CA), an inert fluorescent dye conjugated to an antibody that binds to the 75 neurotrophin receptor expressed only in cholinergic neurons of the basal forebrain. After intracerebroventricular injection, Cy3-192 IgG retrogradely labels only cholinergic neurons of the basal forebrain that project to the hippocampus (Hartig et al., 1998a; Wu et al., 2000). Injection of Cy3-192 IgG was performed based on a previously described protocol (Wu et al., 2000). Postnatal day 22-27 Sprague Dawley rats $(50-70 \mathrm{~g})$ were anesthetized with an intraperitoneal injection of sodium pentobarbital (50 mg/kg; 0.05\% Somnotol; MTC Pharmaceuticals, Hamilton, Ontario, Canada) and were given a subcutaneous injection of $0.02 \%$ of atropine. The rats were then placed in a stereotaxic frame (Narishige, Tokyo, Japan), and $5 \mu$ l of 1:1 diluted Cy3-192 IgG was injected into the left and right ventricles ( $1.1 \mathrm{~mm}$ posterior to bregma, 1.2 $\mathrm{mm}$ lateral from the midline, and $2.6-3.7 \mathrm{~mm}$ below the dura). All procedures were approved by the University of Alberta Health Sciences Animal Policy Welfare Committee (Protocol number 154/04/05).

DBB slice preparation. Brain slices were prepared from Sprague Dawley rats that had received intracerebroventricular injections of Cy3-192 IgG 3-5 d before (Wu et al., 2000). Briefly, animals were anesthetized with halothane and decapitated. The brain was quickly removed and placed in a $3-5^{\circ} \mathrm{C}$ bicarbonate buffered solution that contained (in mM) $140 \mathrm{NaCl}$, $2.5 \mathrm{KCl}, 12 \mathrm{MgCl}_{2}, 1.2 \mathrm{NaH}_{2} \mathrm{PO}_{4}, 2.4 \mathrm{CaCl}_{2}, 25 \mathrm{HCO}_{3}$, and 11 D-glucose, $\mathrm{pH}$ 7.4. All solutions were oxygenated by bubbling with a mixture of $95 \%$ $\mathrm{O}_{2}$ and $5 \% \mathrm{CO}_{2}$. Longitudinal brain slices (300 $\mu \mathrm{m}$ thick) containing the DBB were cut with a Vibratome (Slicer HR2; Sigmann Elektronik, Hüffenhardt, Germany) and incubated for $1 \mathrm{~h}$ at $32^{\circ} \mathrm{C}$ in artificial CSF (ACSF) before recording (in $\mathrm{mm} ; 126 \mathrm{NaCl}, 2.5 \mathrm{KCl}, 1.2 \mathrm{MgCl}_{2}, 1.2$ $\mathrm{NaH}_{2} \mathrm{PO}_{4}, 2.4 \mathrm{CaCl}_{2}, 25 \mathrm{NaHCO}_{3}$ and $11 \mathrm{~mm}$ D-glucose; $\mathrm{pH} 7.4$ ).

Recordings from $D B B$ neurons. DBB slices were bath perfused with $\operatorname{ACSF}\left(23-25^{\circ} \mathrm{C}\right)$ at a rate of $1.5 \mathrm{ml} / \mathrm{min}$ and visualized under an Axioscope 2 Fs microscope (Zeiss, Oberkochen, Germany) at $60 \times$ magnification. Cy3-192 IgG-labeled neurons (cholinergic neurons) were selected using the appropriate filter for Cy3 (546 nm excitation and 575$640 \mathrm{~nm}$ emission). Individual neurons were then visualized under $60 \times$ magnification using differential infrared contrast optics. DBB cells were recorded using the whole-cell patch-clamp technique (Easaw et al., 1997). The internal pipette solution was composed of (in mM) $140 \mathrm{~K}^{+}$gluconate, $2 \mathrm{KCl}, 5 \mathrm{HEPES}, 5 \mathrm{MgATP}, 0.5 \mathrm{NaGTP}$, and $10 \mathrm{EGTA}$, and the
$\mathrm{pH}$ was raised to between 7.2 and 7.3 with potassium hydroxide. The internal solution had an osmolarity of $280 \mathrm{~mm}$. Patch-clamp electrodes (thin wall with filament, $1.5 \mathrm{~mm}$; World Precision Instruments, Sarasota, FL) were pulled with a Narishige (PP-83) puller to yield electrodes with resistances of 2-5 M $\Omega$. Cells recorded with serial resistance higher than $10 \mathrm{M} \Omega$ in whole-cell configuration were discarded. The relatively low access resistance (average, 6.6 $\mathrm{M} \Omega$ ) and small amplitude of currents (usually $<100 \mathrm{pA}$ ) resulted in a $<1 \mathrm{mV}$ voltage drop under our experimental condition, and hence no access resistance compensation was applied. Signals were acquired at a bandwidth of $10 \mathrm{kHz}$ and filtered with a $2 \mathrm{kHz}$ low-pass Bessel filter using an Axopatch 200B amplifier (Molecular Devices, Sunnyvale CA). Miniature EPSCs (mEPSCs) were isolated in voltage-clamp mode at a holding potential of $-60 \mathrm{mV}$ in the presence of $1 \mu \mathrm{M}$ tetrodotoxin (TTX) and either $10 \mu \mathrm{M}$ bicuculline or $50 \mu \mathrm{M}$ picrotoxin, $\mathrm{GABA}_{\mathrm{A}}$ receptor antagonists (see Fig. $1 \mathrm{~F}$ ). Both antagonists at the given concentration are capable of completely abolishing GABA IPSCs. $_{\mathrm{A}}$ In some experiments, previously described electrophysiological criteria were used to identify cholinergic neurons such as a lack of a hyperpolarizing sag and the presence of burst firing on depolarization (Wu et al., 2000). mEPSCs were recorded using pClamp 9.0 for at least 5 min in control conditions, during the presence of treatment and in washout. Washout of any treatment usually takes $10 \mathrm{~min}$ before recordings for mEPSCs.

Statistical analysis. The data were analyzed with Clampfit 9.2 (Molecular Devices) using a template search (Clements and Bekkers, 1997). A template was created based on the average of at least 10 mEPSCs. Average values were expressed as mean $\pm \mathrm{SE}$, and statistical significance was evaluated by means of the two-tailed Student's paired and unpaired $t$ test. The significance level for the $t$ tests was set at $p<0.05$. KolmogorovSmirnov (K-S) testing was also used to examine differences, and the significance level of this test was set at $p<0.0005$. The mEPSC parameters included the following: peak amplitude, the baseline to the peak value; rise time, the amount of time on the rising phase of mEPSC between 10 and $90 \%$ of the peak; decay time, the amount of time on the falling phase of the mEPSC between 90 and $10 \%$ of the peak; area, an integral of the mEPSCs (measured in units of $n A * m s$ ).

Immunohistochemistry. Rats that received previous injections of Cy3192 IgG were anesthetized with halothane, and intraperitoneal urethane was administered. Animals were then sequentially perfused with PBS and $4 \%$ formaldehyde in $0.1 \%$ PBS that was kept at $3-5^{\circ} \mathrm{C}$. The brains were removed and incubated for $1 \mathrm{~h}$ in $4 \%$ formaldehyde in PBS. Afterward, the brains were stored in $10 \%$ sucrose solution. Fifty micrometer coronal DBB brain slices were cut using a cryostat and blocked with $1 \%$ bovine serum albumin for $1 \mathrm{~h}$. Slices were then incubated overnight with primary rabbit antibodies for vesicular choline acetyltransferase (vChAT) at $3-5^{\circ} \mathrm{C}$ (1:2500 dilution; Santa Cruz Biotechnology, Santa Cruz, CA). Slices were washed three times in PBS, incubated with Alexa 488 chicken anti-rabbit antibodies for $1.5 \mathrm{~h}$ to yield green fluorescence (1:400 dilution), and washed three times in PBS. Slides were air dried and dehydrated with ethanol and xylene before being coverslipped with Cytoseal (Canada Wide Scientific, Ottawa, Ontario, Canada). Slides were viewed on a Zeiss Axioplan 2, and images were captured with a Zeiss Axiocam MRc camera and saved with MGrab software. In 14 randomly selected sections through the DBB, Cy3-192 IgG-positive neurons and those that were also vChAT positive were counted

Drugs. $\mathrm{A} \beta_{1-42}$ and $\mathrm{A} \beta_{42-1}$ were purchased from American Peptide (Sunnyvale, $C A$ ). Stock solution of $A \beta$ was prepared by dissolving the peptides at $1 \mathrm{~mm}$ in deionized water and stored in aliquots at $-70^{\circ} \mathrm{C}$. On the day of the experiment, $\mathrm{A} \beta$ peptides were diluted in external perfusion medium (ACSF) just before the time of application. All voltage-clamp experiments were conducted in the presence of $1 \mu \mathrm{M}$ TTX and either 10 $\mu \mathrm{M}$ bicuculline or $50 \mu \mathrm{M}$ picrotoxin. All chemicals were purchased from Sigma (St. Louis, MO), except for TTX (purchased from Alamone Labs, Jerusalem, Israel) and (RS)- $\alpha$-methyl-4-carboxyphenyglycine (MCPG; purchased from Tocris (Ellisville, MO), a nonselective group I/II mGluR antagonist. All drugs were bath applied (perfusion rate of $1.5-3 \mathrm{ml} / \mathrm{min}$ ) through a four-way valve system, which allowed complete exchange of perfusate in less then half a minute. The nAChR and mGluR antagonists 

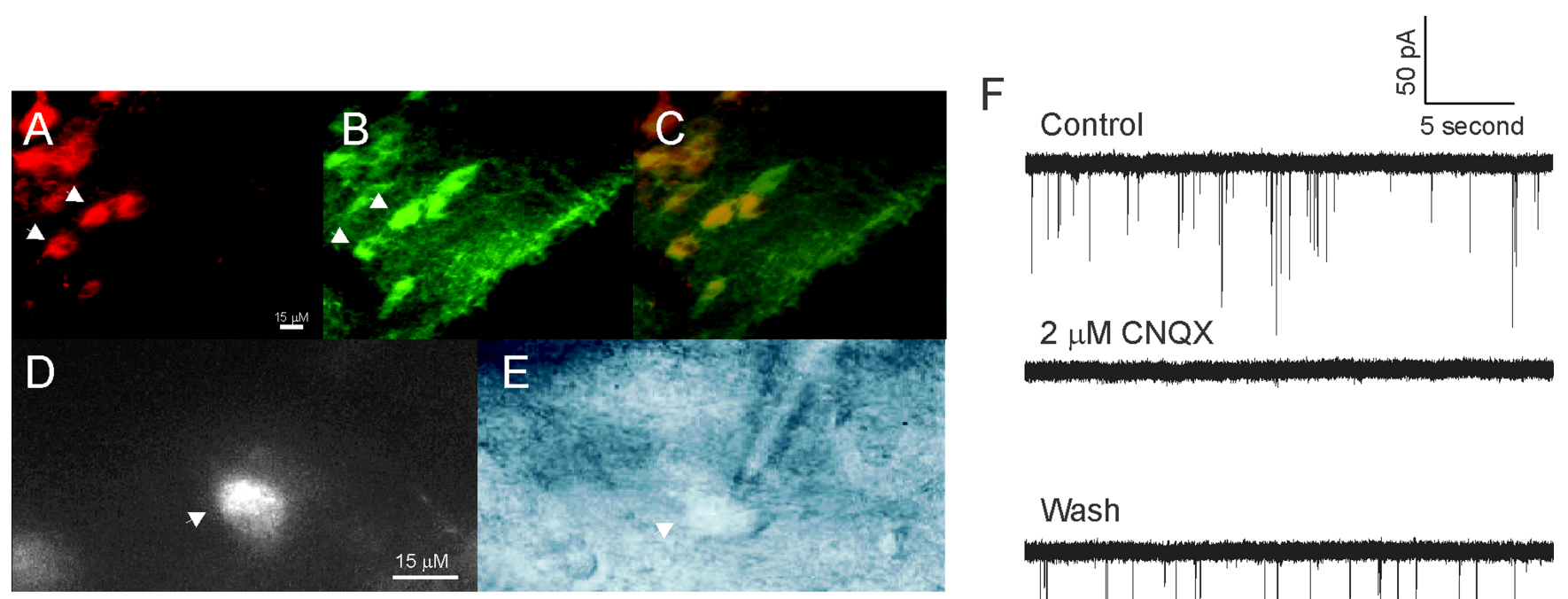

Figure 1. Identification of cholinergic neurons and $m E P S C$ in the DBB. $A, B$, Horizontal slice of the rat forebrain containing the DBB viewed under a filter for Cy3-192 $\mathrm{lg} G$ (red) and a filter for Alexa 488 (green; vChAT). C, The overlay of images $\boldsymbol{A}$ and $\boldsymbol{B}$ shows that Cy3-192 lgG labels cells that are also vChAT positive (arrowheads in $\boldsymbol{A}, \boldsymbol{B}$ ). The calibration bar in $\boldsymbol{A}$ is the same for $\boldsymbol{B}$ and $\boldsymbol{C}$. $\boldsymbol{D}, \mathrm{A}$ Cy3-192 IgG-labeled cell in a slice viewed under a $60 \times$ water-immersion lens before recording (arrowhead). $\boldsymbol{E}$, Differential infrared contrast image of the same cell viewed in $\boldsymbol{C}$ being recorded (arrowhead). The calibration bar in $\boldsymbol{D}$ is the same for $\boldsymbol{E}$. $\boldsymbol{F}$, $\mathrm{mEPSC}$ activity in neurons of DBB is reversibly abolished by CNQX, an AMPA/kainate receptor antagonist.

were applied by continual bath application for 10 min before $\mathrm{A} \beta_{1-42}$ application.

\section{Results}

\section{Cy3-192 IgG labeling colocalizes with vChAT labeling in}

\section{DBB neurons}

Immunohistochemical experiments demonstrated colocalization of Cy3-192 IgG labeling with vChAT labeling (Fig. 1 A-C). Of the Cy3-192 IgG-positive cells, 80.4\% also showed vChAT labeling, confirming previous studies reporting most Cy3-192 IgG-labeled cells are indeed cholinergic (Hartig et al., 1998; Wu et al., 2000). Figure $1 D$ shows a Cy3-192 IgG-labeled cell viewed under a water-immersion lens at $60 \times$ magnification, and Figure $1 E$ shows the same neuron being patched under differential infrared contrast imaging. The average capacitance of Cy3-192 IgG-labeled neurons was $18.9 \pm 0.5 \mathrm{pF}$, and the average access resistance was $6.6 \pm 0.2 \mathrm{M} \Omega(n=50)$. The average conductance of the cells was $2.85 \pm 0.25 \mathrm{nS}(n=50)$.

\section{CNQX abolishes mEPSCs in DBB neurons}

Identity of the neurotransmitter mediating mEPSCs was examined with the AMPA/kainate receptor antagonist 6-cyano-7nitroquinoxaline-2, 3-dione (CNQX). In the presence of $1 \mu \mathrm{M}$ TTX and $50 \mu \mathrm{M}$ picrotoxin, mEPSC recordings were obtained from Cy3-192 IgG-labeled neurons, whereas the cells were held at a membrane potential of $-60 \mathrm{mV}$ (Fig. $1 F$ ). Bath application of 2 $\mu \mathrm{M}$ CNQX completely abolished all mEPSC events (Fig. $1 F$ ). The CNQX-induced abolition of mEPSCs recovered after 15-20 min of washout of the drug under our experimental conditions (Fig. $1 F)$. CNQX-induced abolition of mEPSCs was observed in a total of five identified cholinergic neurons. These data demonstrate that the recorded mEPSCs were glutamatergic and mediated by AMPA and kainate receptors.

\section{$A \boldsymbol{\beta}_{1-42}$ increases mEPSC frequency but not amplitude in DBB neurons}

In 15 of $28(54 \%)$ identified cholinergic neurons, bath application of $100 \mathrm{~nm} \mathrm{~A} \beta_{1-42}$ significantly increased mEPSC frequency.
Figure $2 \mathrm{~A}$ demonstrates sample traces of mEPSCs recorded from an identified cholinergic neuron under control conditions with application of $100 \mathrm{nM} \mathrm{A} \beta_{1-42}$ and after washout of the peptide. An obvious increase in mEPSC frequency in response to application of $A \beta_{1-42}$ is observed. The response is time independent because subsequent application of $\mathrm{A} \beta_{1-42} 15 \mathrm{~min}$ after washout reproduces the increase in $\mathrm{mEPSC}$ frequency (data not shown). Figure $2 B$ shows the cumulative frequency histogram of an mEPSC interevent interval (top panel) and amplitude (bottom panel) in the same cell. Application of the K-S statistical test to this and other individual cells demonstrated the interevent interval to be significantly decreased during application of $\mathrm{A} \beta_{1-42}$, whereas there was no change in amplitude. In a total of 15 neurons, the average increase in frequency of mEPSCs $(29.6 \pm 5.4 \%)$ in response to application of $\mathrm{A} \beta_{1-42}$ exhibited a significant change, because the average frequency was $0.89 \pm 0.16 \mathrm{~Hz}$ under control conditions increased to $1.21 \pm 0.28 \mathrm{~Hz}$ in the presence of $100 \mathrm{nM} \mathrm{A} \beta_{1-42}$ and recovered to $0.92 \pm 0.28 \mathrm{~Hz}$ during washout (Fig. $2 C$, top) $(p<0.05)$. However, the peak amplitude of mEPSCs did not change significantly in these neurons because the control peak amplitude was $-37.1 \pm 1.7 \mathrm{pA}$ and the peak amplitude in the presence of $100 \mathrm{nM} \mathrm{A} \beta_{1-42}$ and during the washout period was $-36.8 \pm 1.9$ and $-35.9 \pm 1.7 \mathrm{pA}$, respectively (Fig. $2 C$, bottom $)(p>0.05)$. Examination of other kinetic parameters of the mEPSCs revealed that there were no significant differences in rise time, decay time, and area between control conditions and $100 \mathrm{~nm} \mathrm{~A} \beta_{1-42}$ treatment (Table 1).

Reverse peptide $A \boldsymbol{\beta}_{42-1}$ does not alter frequency or amplitude of mEPSCs

To confirm the specificity of the $\mathrm{A} \beta_{1-42}$-evoked alteration in mEPSC frequency, we applied $100 \mathrm{nM} \mathrm{A} \beta_{42-1}$ to identified cholinergic neurons that had previously demonstrated an $\mathrm{A} \beta_{1-42^{-}}$ mediated increase in frequency. As observed in sample traces of mEPSCs (Fig. 2D), no obvious change in frequency was observed. Figure $2 E$ shows cumulative frequency histograms of an mEPSC interevent interval (top panel) and amplitude (bottom panel) in the 
A

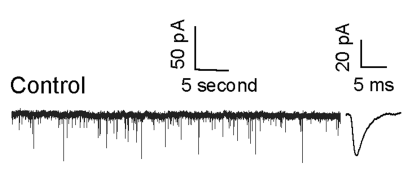

$100 \mathrm{nM} \mathrm{A} \beta_{1-42}$

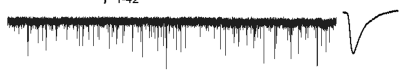

Wash

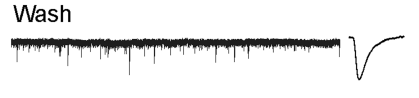

D

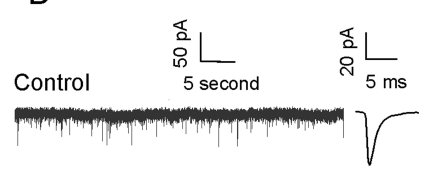

$100 \mathrm{nM} \mathrm{A} \beta_{42-1}$

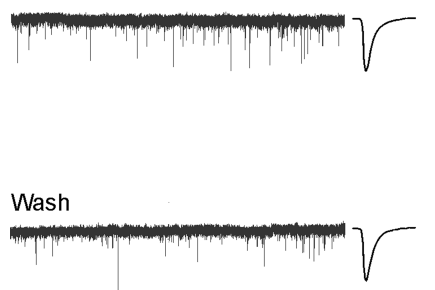

B
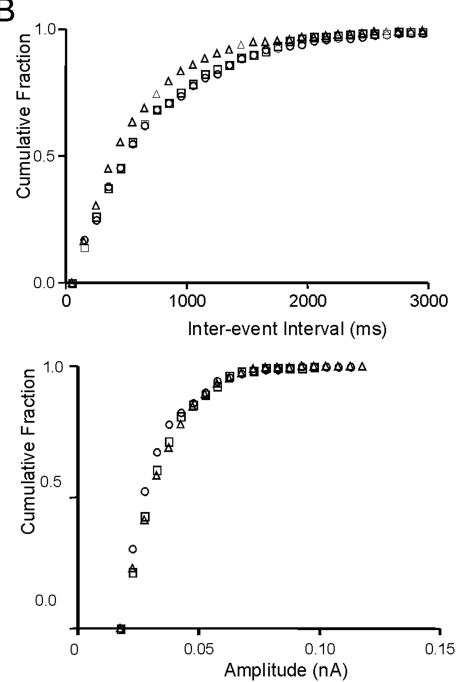

$\mathrm{E}$
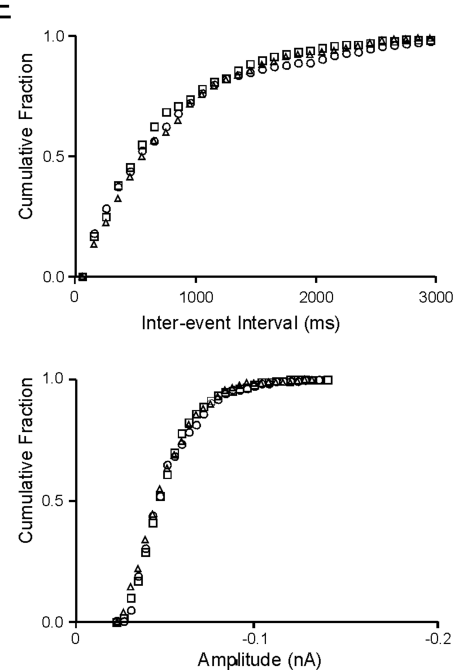

C
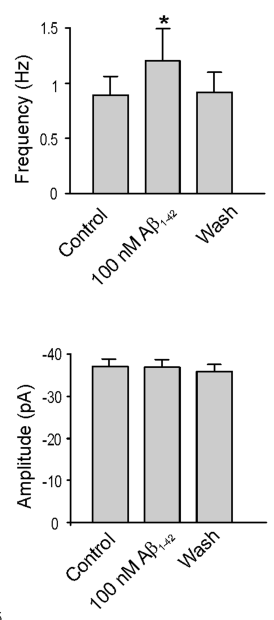

F

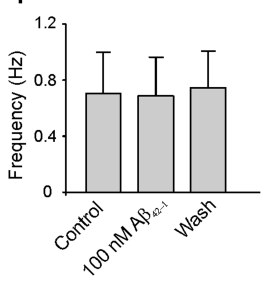

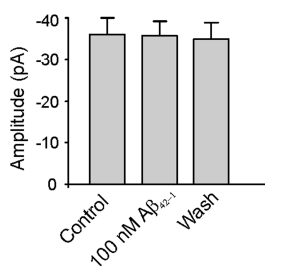

Figure 2. $A \beta_{1-42}$, but not the reverse peptide $A \beta_{42-1}$, increases mEPSC frequency but not amplitude in DBB neurons. $A$, Sample traces of mEPSCs under control conditions, during application of $A \beta_{1-42}$, and during washout from a cholinergic DBB neuron. Insets beside each trace show averaged mEPSCs from 100 consecutive events under the three recording conditions. $\boldsymbol{B}$ Cumulative probability analysis of $\mathrm{mEPSC}$ of the same neuron as in $\boldsymbol{A}$ showing the distribution of the interevent interval (top) and peak amplitude (bottom) during control conditions (square), during application of $100 \mathrm{~nm} \mathrm{~A} \beta_{1-42}$ (triangle), and during washout (circle). $A \beta_{1-42}$ caused a significant decrease in the interevent interval of $m E P S C s$ without changing the distribution of the amplitude ( $p<0.0005$ ). C, Average frequency of mEPSCs (top) and average amplitude of mEPSCs (bottom) under control conditions, during application of $A \beta_{1-42}$, and during washout $\left(n=15 ;{ }^{*} p<0.05\right.$, significant difference from control). $D$, Sample traces of mEPSCs under control conditions, during application of $A \beta_{42-1}$, and during washout from another cholinergic DBB neuron. Insets beside each trace show averaged mEPSCs from 100 consecutive events under the three recording conditions. $E$, The cumulative frequency histogram of an mEPSC interevent interval (top) and amplitude (bottom) from the same cell as in $\boldsymbol{D}$ demonstrates no significant change between control conditions (square) and during application of $100 \mathrm{~nm} \mathrm{~A} \beta_{42-1}$ (triangle). Washout is denoted by a circle. $F$, Average frequency of mEPSCs (top) and average amplitude of mEPSCs (bottom) during application of $A \beta_{42-1}$ showing no significant difference between the peptide application and control or washout $(n=4 ; p>0.05)$. Error bars indicate SEM.

Table 1. Kinetic parameters of cholinergic neurons that demonstrate an increase in mEPSC frequency in the presence of 100 пм $A \beta_{1-42}$

\begin{tabular}{lccc}
\hline Statistic & Control $^{a}$ & $100 \mathrm{~nm} \mathrm{~A}_{1-42}{ }^{a}$ & Recovery $^{a}$ \\
\hline Peak amplitude (pA) & $-37.1 \pm 1.7$ & $-36.8 \pm 1.9$ & $-35.9 \pm 1.7$ \\
$10-90 \%$ rise time (ms) & $0.73 \pm 0.09$ & $0.80 \pm 0.10$ & $0.81 \pm 0.10$ \\
$90-10 \%$ decay time (ms) & $2.84 \pm 0.80$ & $2.88 \pm 0.31$ & $2.86 \pm 0.32$ \\
Area (nA * ms) & $-0.068 \pm 0.007$ & $-0.068 \pm 0.007$ & $-0.068 \pm 0.007$ \\
\hline
\end{tabular}

${ }^{a}$ No significant differences were observed between the three groups. Values are mean $\pm \operatorname{SEM}(n=15 ; p>0.05)$.

same cell. In four neurons exhibiting previous $\mathrm{A} \beta_{1-42}$-mediated increase in frequency, applications of $\mathrm{A} \beta_{42-1}$ did not affect the frequency of mEPSCs $(0.69 \pm 0.27 \mathrm{~Hz}$ under control conditions, $0.71 \pm 0.29 \mathrm{~Hz}$ in the presence of $100 \mathrm{nM} \mathrm{A} \beta_{42-1}$, and $0.72 \pm 0.24$ $\mathrm{Hz}$ after washout; $p>0.05$ ) (Fig. $2 F$, top). The average peak amplitude under control conditions was $-41.1 \pm 3.9 \mathrm{pA}$, whereas in the presence of $\mathrm{A} \beta{ }_{-}{ }_{42-1}$ and after washout, the peak amplitude was $-40.0 \pm 5.6$ and $-39.8 \pm 3.9$ pA, respectively (Fig. $2 F$, bottom) $(p>0.05)$. No significant differences in other kinetic parameters were observed between control conditions and application of $100 \mathrm{nM} \mathrm{A} \beta_{42-1}$ (data not shown).

$A \beta_{1-42}$ decreases mEPSC frequency but not amplitude in DBB neurons

In 9 of $28(32 \%)$ identified cholinergic neurons, bath application of $100 \mathrm{~nm}$ $\mathrm{A} \beta_{1-42}$ significantly reduced mEPSC frequency. Figure $3 A$ shows sample traces of the change in mEPSCs recorded from an identified cholinergic neuron in response to application of $100 \mathrm{~nm} \mathrm{~A} \beta_{1-42}$. An obvious decrease in EPSC frequency was observed in the presence of $A \beta_{1-42}$. This decrease was reproducible with subsequent applications of $A \beta_{1-42}$ (data not shown). Figure $3 B$ shows the cumulative frequency histogram of an mEPSC interevent interval (top panel) and amplitude (bottom panel) in the same cell. Application of the $\mathrm{K}-\mathrm{S}$ test to this cell demonstrated the interevent interval was significantly increased, whereas there was no significant change in amplitude. In nine neurons, application of $\mathrm{A} \beta_{1-42}$ decreased the frequency of $\mathrm{mEP}$ SCs by $31.8 \pm 4.8 \%$. The frequency decreased from $0.97 \pm 0.21 \mathrm{~Hz}$ under control condition to $0.68 \pm 0.18 \mathrm{~Hz}$ in the presence of $100 \mathrm{~nm} \mathrm{~A} \beta_{1-42}$. After washout, the frequency recovered to $0.92 \pm 0.23 \mathrm{~Hz}$ (Fig. $3 C$, top) $(p<0.05)$. In a similar manner to neurons exhibiting an $\mathrm{A} \beta_{1-42^{-}}$ mediated increase in mEPSC frequency, no significant change in peak amplitude was observed for cells showing a decrease in mEPSC frequency. Under control conditions, the peak amplitude was $-34.7 \pm$ $2.7 \mathrm{pA}$, whereas in the presence of $100 \mathrm{nM}$ $\mathrm{A} \beta_{1-42}$ and during the washout, the peak amplitude was $-31.4 \pm 2.3$ and $-33.3 \pm$ 2.7 pA, respectively (Fig. 3C, bottom) $(p>0.05)$. Examination of other kinetic parameters of the mEPSCs also revealed that there were no significant changes in rise time, decay time, and area between control conditions and $100 \mathrm{nM} \mathrm{A} \beta_{1-42}$ treatment of cholinergic neurons (Table 2). In 4 of 28 (14\%) identified cholinergic neurons, bath application of $100 \mathrm{~nm}$ 
$\mathrm{A} \beta_{1-42}$ led to no significant change in frequency and peak amplitude of mEPSCs (data not shown).

The $A \boldsymbol{\beta}_{1-42}$-mediated increase in mEPSC frequency is antagonized by the $n A C h R$ antagonist dihydro- $\beta$ erythroidine but not $\alpha$-bungarotoxin

Because $A \beta_{1-42}$ has been found to have high affinity to nAChRs and to be capable of influencing the function of these receptors (Wang et al., 2000a; Pettit et al., 2001; $\mathrm{Fu}$ and Jhamandas, 2003), we used dihydro- $\beta$-erythroidine (DH $\beta \mathrm{E}$ ) (a selective $\alpha 4 \beta 2$ nAChR antagonist) and $\alpha$-bungarotoxin (a selective non- $\alpha 7$ nAChR antagonist) to investigate the possible receptor subtypes involved in the $\mathrm{A} \beta_{1-42}$-mediated change in mEPSC frequency. We first tested the effect of $\mathrm{DH} \beta \mathrm{E}$ on the $\mathrm{A} \beta_{1-42}$-mediated increase in $\mathrm{mEP}$ SCs in identified cholinergic neurons. Bath application of $100 \mathrm{nM} \mathrm{A} \beta_{1-42}$ to a neuron increased mEPSC frequency (Fig. $4 A$, left). However, in the presence of 10 $\mu \mathrm{M} \mathrm{DH} \beta \mathrm{E}$, subsequent application of 100 nM $\mathrm{A} \beta_{1-42}$ to the same neuron did not elicit a similar increase in frequency (Fig. $4 A$, left). In five neurons, the $\mathrm{A} \beta_{1-42^{-}}$ mediated increase in mEPSC frequency was $25.4 \pm 7.9 \%$ under control conditions and $2.4 \pm 5.6 \%$ in the presence of $10 \mu \mathrm{M}$ $\mathrm{DH} \beta \mathrm{E}$ (Fig. $4 A$, right) $(p<0.05)$.

We also tested the effect of $\alpha$-bungarotoxin on the $\mathrm{A} \beta_{1-42}$-mediated increase in mEPSCs in identified cholinergic neurons. Bath application of $100 \mathrm{nM}$ $\mathrm{A} \beta_{1-42}$ to a neuron that demonstrated an $\mathrm{A} \beta_{1-42}$-mediated increase in mEPSCs continued to reveal a persistent increase in mEPSC frequency in the presence of $100 \mathrm{~nm} \alpha$-bungarotoxin, an $\alpha 7 \mathrm{nAChR}$ antagonist (Fig. $4 \mathrm{~B}$, left). In eight neurons, the $\mathrm{A} \beta_{1-}$ 42 -mediated average increase in mEPSC frequency was $34.5 \pm$ $6.9 \%$ under control conditions and $36.3 \pm 8.4 \%$ in the presence of $100 \mathrm{nM} \alpha$-bungarotoxin (Fig. $4 B$, right) $(p>0.05)$. As we expected, no significant change in average peak amplitude or other kinetic parameters of mEPSCs was observed in the presence of $100 \mathrm{nM} \mathrm{A} \beta_{1-42}$ alone or with coapplication of $100 \mathrm{nM} \mathrm{A} \beta_{1-42}$ and either of the two nAChR antagonists (data not shown). Additionally, bath application of $10 \mu \mathrm{M} \mathrm{DH} \beta \mathrm{E}$ or $\alpha$-bungarotoxin alone to two identified cholinergic neurons did not significantly change frequency and peak amplitude of mEPSCs (data were shown).

\section{$A \beta_{1-42}$-mediated decrease in mEPSC frequency is not antagonized by $\mathrm{nAChR}$ antagonist but by nonselective mGluR antagonist}

We also examined whether the $\mathrm{A} \beta_{1-42}$-mediated decrease in mEPSC frequency in identified cholinergic neurons was mediated by $n A C h R s$. The left panel of Figure $5 A$ shows a neuron that had a decrease in mEPSC in response to $100 \mathrm{~nm} \mathrm{~A} \beta_{1-42}$. Subsequent application of $100 \mathrm{nM} \mathrm{A} \beta_{1-42}$ to the same neuron in the presence of $10 \mu \mathrm{M} \mathrm{DH} \beta \mathrm{E}$ did not inhibit the decrease in frequency (Fig. $5 A$, left). In five neurons, the $\mathrm{A} \beta_{1-42}$-mediated depresence of $100 \mathrm{~nm} A \beta_{1-42}$
B
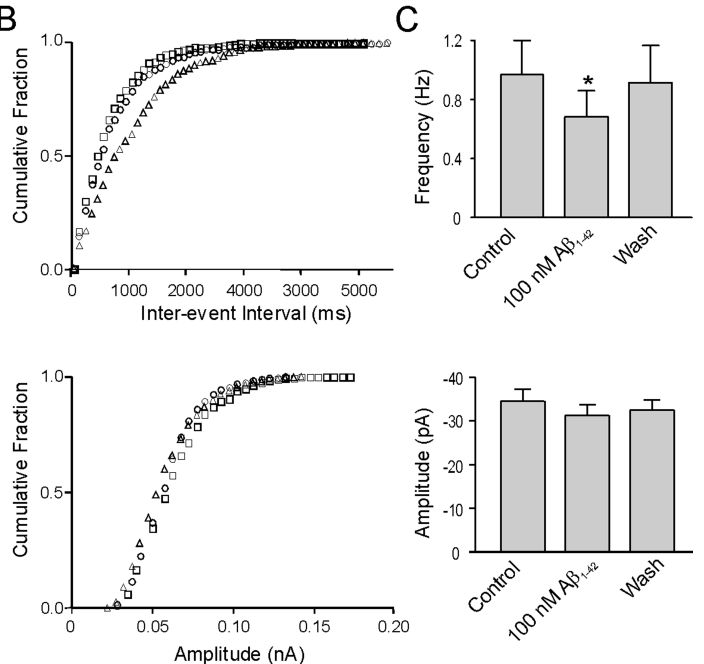

Figure 3. $A \beta_{1-42}$ also decreases mEPSC frequency but not amplitude in some DBB neurons. $A$, Sample traces of mEPSCs under increase in the interevent interval of $\mathrm{mEPSCS}$ without changing the distribution of the amplitude $(p<0.0005)$. Average frequency of mEPSCs (top) and average amplitude of mEPSCs (bottom) under control conditions, during application of

Table 2. Kinetic parameters of cholinergic neurons that demonstrate a decrease in mEPSC frequency in the

\begin{tabular}{|c|c|c|c|}
\hline Statistic & Control $^{a}$ & $100 \mathrm{~nm} A \beta_{1-42^{a}}$ & Recovery $^{a}$ \\
\hline Peak amplitude (pA) & $-35.0 \pm 2.9$ & $-31.4 \pm 2.3$ & $-33.3 \pm 2.7$ \\
\hline $10-90 \%$ rise time (ms) & $0.65 \pm 0.04$ & $0.64 \pm 0.06$ & $0.63 \pm 0.06$ \\
\hline $90-10 \%$ decay time (ms) & $2.56 \pm 0.34$ & $2.53 \pm 0.34$ & $2.51 \pm 0.31$ \\
\hline Area $\left(n A_{*} m s\right)$ & $-0.063 \pm 0.006$ & $-0.056 \pm 0.006$ & $-0.058 \pm 0.006$ \\
\hline
\end{tabular}

crease in mEPSC frequency was $27.5 \pm 3.7 \%$ under control conditions and $24.5 \pm 2.8 \%$ in the presence of $10 \mu \mathrm{M} \mathrm{DH} \beta \mathrm{E}$ (Fig. $5 \mathrm{~A}$, right) $(p>0.05)$. In contrast, subsequent bath application of $\mathrm{A} \beta_{1-42}$ in the presence of $100 \mathrm{nM} \alpha$-bungarotoxin to neurons exhibiting an $\mathrm{A} \beta_{1-42}$-mediated decrease in mEPSC frequency also did not affect the decrease in mEPSC frequency (Fig. $5 B$, left). In four neurons, the $\mathrm{A} \beta_{1-42}$-mediated decrease in mEPSC frequency was $24.1 \pm 3.4 \%$ under control conditions and $22.9 \pm$ $6.5 \%$ in the presence of $100 \mathrm{nM} \alpha$-bungarotoxin, respectively (Fig. $5 B$, right) $(p>0.05)$.

Because presynaptic inhibition of synaptic transmission via activation of mGluRs occurs very widely in the brain, including within the DBB (Easaw and Jhamandas, 1994; Anwyl, 1999), we used MCPG (a nonselective group I/II mGluR antagonist) to investigate whether activation of such receptors is involved in an $\mathrm{A} \beta_{1-42}$-mediated decrease in mEPSC frequency. The mGluR antagonist was delivered by continual bath application at least 10 min before $\mathrm{A} \beta_{1-42}$ application. Application of MCPG alone did not affect the frequency of mEPSCs, indicating presynaptic inhibition via activation of mGluRs is not likely to occur through tonic glutamate release. In an identified cholinergic neuron that demonstrated an $A \beta_{1-42}$-mediated decrease in mEPSC frequency, subsequent application of $100 \mathrm{~nm} \mathrm{~A} \beta_{1-42}$ in the presence of $250 \mu \mathrm{M}$ MCPG did not elicit a similar decrease in frequency (Fig. $5 C$, left). In four neurons, the $\mathrm{A} \beta_{1-42}$-mediated decrease in mEPSC frequency was $19.8 \pm 5.02 \%$ under control conditions 


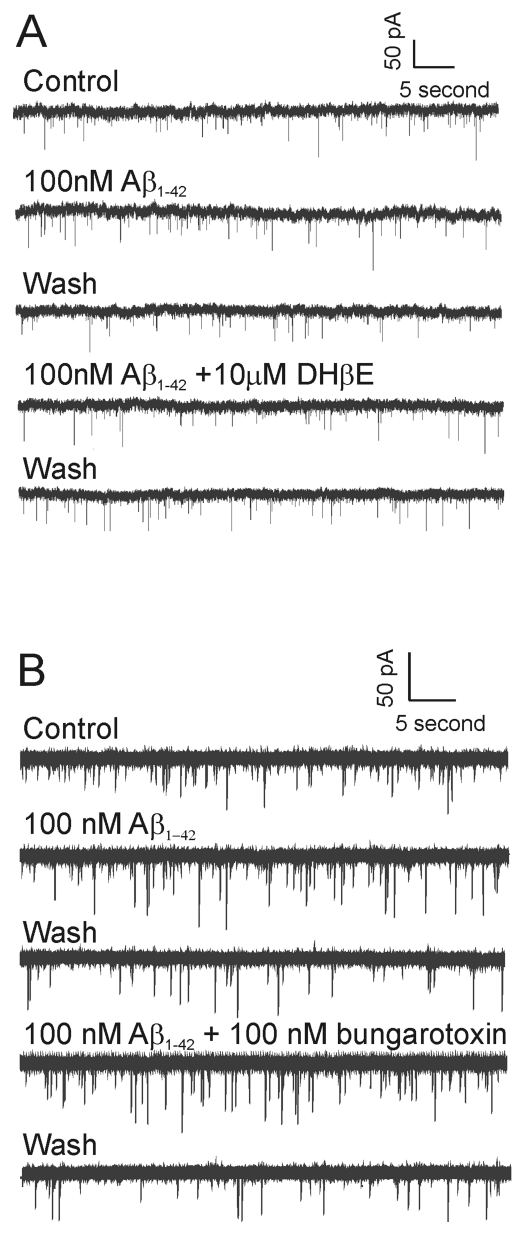

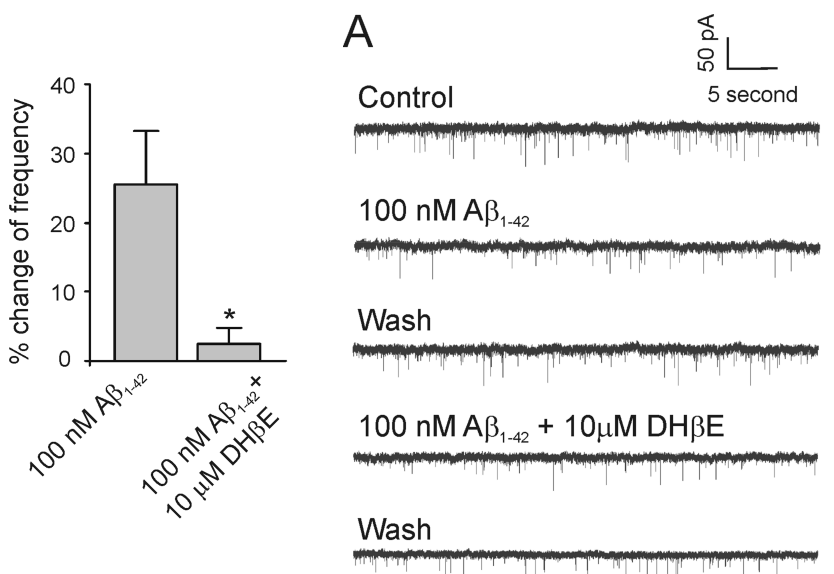
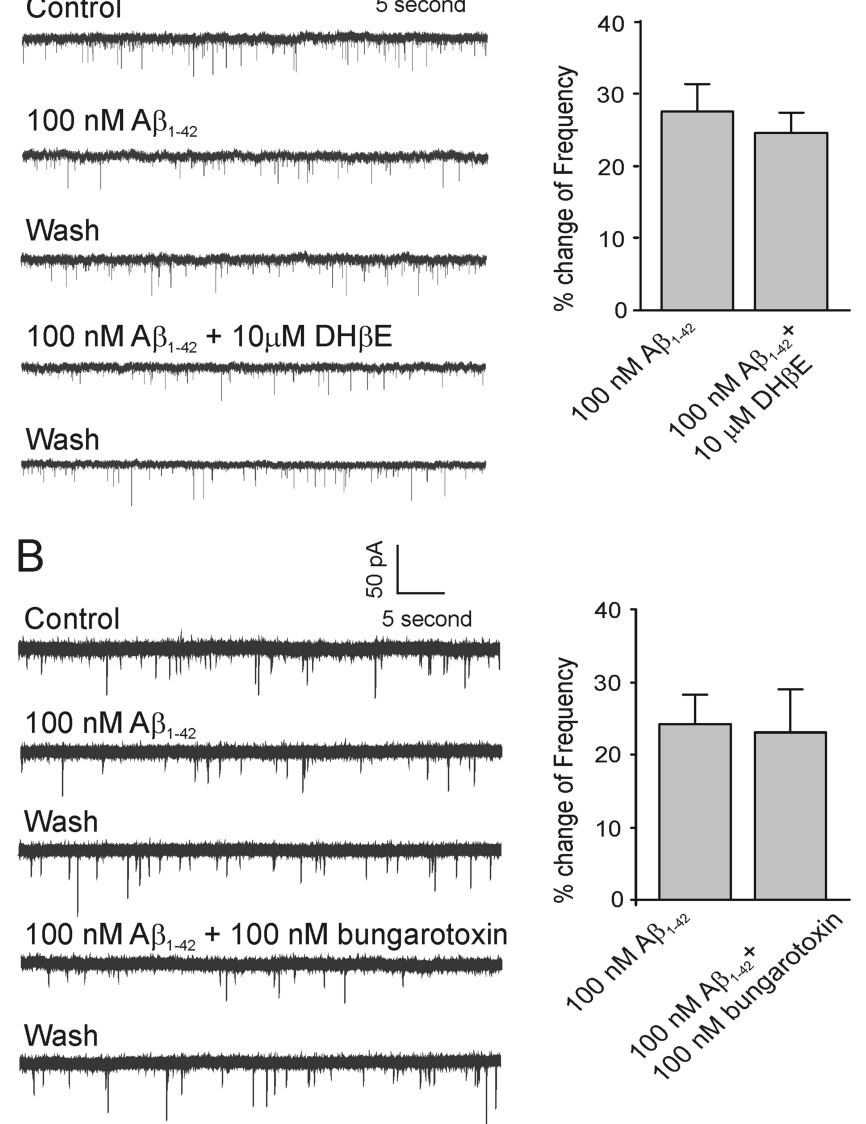

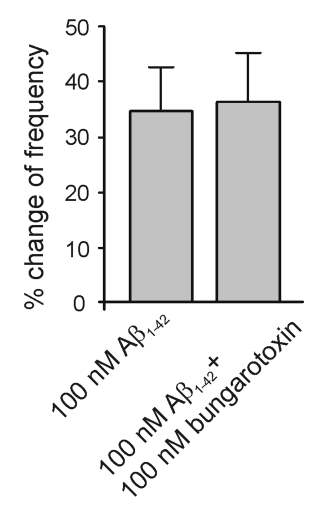

Figure 4. $\quad A \beta_{1-42}$-mediated increase in $m E P S C$ frequency is antagonized by non- $\alpha 7$ but not $\alpha 7 \mathrm{nAChR}$ antagonists. $\boldsymbol{A}$, Left, Sample traces of mEPSCs from a cholinergic DBB neuron in response to $A \beta_{1-42}$ and a combination of $A \beta_{1-42}$ and DH $\beta E$ (a non- $\alpha 7$ nAChR antagonist), respectively. Right, Histograms depicting the average effect of $10 \mu \mathrm{m} \mathrm{DH} \beta \mathrm{E}$ on the $\mathrm{A} \beta_{1-42^{-}}$ mediated increase in mEPSC frequency $\left(n=5 ;{ }^{*} p<0.05\right.$, significant difference from control). $B$, Left, Sample traces of $m E P S C s$ from another cholinergic DBB neuron in response to $A \beta_{1-42}$ and a combination of $A \beta_{1-42}$ and $\alpha$-bungarotoxin ( $\alpha 7 \mathrm{nAChR}$ antagonist), respectively. Right, Histograms depicting the average effect of $100 \mathrm{nM} \alpha$-bungarotoxin on the $A \beta_{1-42}$-mediated increase in $\mathrm{mEPSC}$ frequency $(n=8 ; p>0.05)$. Error bars indicate SEM.

and $1.3 \pm 2.9 \%$ in the presence of $250 \mu \mathrm{M} \mathrm{MCPG} \mathrm{(Fig.} 5 C$, right) $(p<0.05)$. However, $250 \mu \mathrm{M}$ MCPG did not show a significant effect on the $\mathrm{A} \beta_{1-42}$-mediated increase in mEPSC frequency (data not shown).

\section{Discussion}

In this study, the effects of $\mathrm{A} \beta_{1-42}$ on excitatory synaptic events in identified cholinergic DBB neurons were examined. mEPSCs recorded from the neurons, held at a membrane potential of -60 $\mathrm{mV}$, were mediated by the AMPA and kainate subtypes of glutamate receptors because application of CNQX, an AMPA/kainate receptor antagonist, completely abolished such events. Although evoked glutamatergic EPSCs have been recorded in the DBB, such reports are infrequent (Easaw et al., 1997; Momiyama and Fukazawa, 2007). In part, this is related to geometrical considerations in coronal and horizontal forebrain slices, which do not optimally preserve glutamate afferents (originating from prefrontal cortex and other sources) to the DBB and thus make electrical stimulation-evoked EPSCs difficult (Jhamandas and Bourque, 2000). We therefore focused our studies on glutamatemediated mEPSCs in the DBB. In a majority of cholinergic neu-
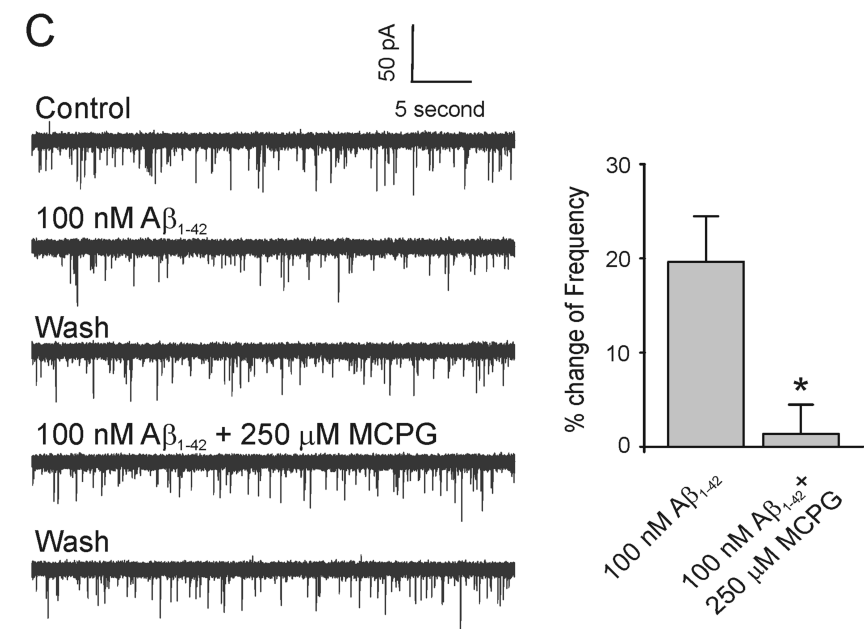

Figure 5. $A \beta_{1-42}$-mediated decrease in mEPSC frequency is not antagonized by $\mathrm{nAChR}$ antagonists but by mGluR antagonists. $A$, Left, Sample traces of mEPSCs from a cholinergic DBB neuron in response to $A \beta_{1-42}$ and a combination of $A \beta_{1-42}$ and $D H \beta E$ (non- $\alpha 7$ nAChR antagonist), respectively. Right, Histograms depicting the average effect of $D H \beta E$ on the $A \beta_{1-42^{-}}$ mediated decrease in mEPSC frequency $(n=5 ; p>0.05) . \boldsymbol{B}$, Left, Sample traces of mEPSCS from another cholinergic DBB neuron in response to $A \beta_{1-42}$ and a combination of $A \beta_{1-42}$ and $\alpha$-bungarotoxin ( $\alpha 7 \mathrm{nAChR}$ antagonist), respectively. Right, Histograms depicting the average effect of $\alpha$-bungarotoxin on the A $\beta_{1-42}$-mediated decrease in mEPSC frequency $(n=4 ; p>$ 0.05). C, Left, Sample traces of mEPSCs from another cholinergic DBB neuron in response to $A \beta_{1-42}$ and a combination of $A \beta_{1-42}$ and MCPG (nonselective group I/group II mGluR antagonist), respectively. Right, Histograms depicting the average effect of $\mathrm{DH} \beta \mathrm{E}$ on the $\mathrm{A} \beta_{1-42^{-}}$ mediated decrease in mEPSC frequency $\left(n=4 ;{ }^{*} p<0.05\right.$, significant difference from control). Error bars indicate SEM. 
rons, bath applications of $\mathrm{A} \beta_{1-42}$ significantly increased the frequency of mEPSCs without any significant change in amplitude or kinetic parameters of mEPSCs. This effect of $A \beta_{1-42}$ could be blocked by the non- $\alpha 7, \alpha 4 \beta 2$-selective $\mathrm{nAChR}$ antagonist $\mathrm{DH} \beta \mathrm{E}$ but not by the $\alpha 7$-selective nAChR antagonist $\alpha$-bungarotoxin, suggesting that soluble $A \beta_{1-42}$ is able to modulate presynaptic glutamatergic neurotransmission via activation of $\alpha 4 \beta 2$ nAChRs. In another subset of cholinergic neurons, $A \beta_{1-42}$ decreased the frequency of mEPSCs without significant change in amplitude or kinetic parameters. The $\mathrm{A} \beta_{1-42}$-mediated decrease in frequency was not antagonized by either $\mathrm{DH} \beta \mathrm{E}$ or $\alpha$-bungarotoxin but by the nonselective (group I/II) mGluR antagonist MCPG, suggesting that $\mathrm{A} \beta_{1-42}$ mediates such presynaptic effects through activation of mGluRs. We found no differences in kinetic parameters of the two populations of neurons that responded to $\mathrm{A} \beta_{1-42}$ in an opposite manner. The $\mathrm{A} \beta_{1-42}$ modulation of mEPSC frequency is a specific effect because the inverse sequence peptide $\left(\mathrm{A} \beta_{42-1}\right)$ failed to produce an effect.

Initial binding studies demonstrated that $\mathrm{A} \beta_{1-42}$ binds to $\alpha 7$ $\mathrm{nAChRs}$ with picomolar affinity and to $\alpha 4 \beta 2 \mathrm{nAChRs}$ with nanomolar affinity (Wang et al., 2000a,b). A number of electrophysiological studies, in a variety of in vitro preparations, have demonstrated that $\mathrm{A} \beta_{1-42}$ can exert its effects through both $\alpha 7$ and $\alpha 4 \beta 2$ nAChRs (Pettit et al., 2001; Dineley et al., 2002; Fu and Jhamandas, 2003; Wu et al., 2004; Lamb et al., 2005). However, the precise nature of $\mathrm{A} \beta_{1-42}$ interactions with $\mathrm{nAChRs}$ is controversial because some studies have reported that $\mathrm{A} \beta_{1-42}$ activates nAChRs (Dineley et al., 2002; Fu and Jhamandas, 2003), whereas other studies suggested that $\mathrm{A} \beta_{1-42}$ inhibits nAChRs (Pettit et al., 2001; Wu et al., 2004; Lamb et al., 2005). Both $\alpha 7$ and non- $\alpha 7$ subtypes of nAChRs were reported to be involved in such $A \beta$ mediated interactions. In our study, $\mathrm{A} \beta_{1-42}$ mediated an increase in the frequency of spontaneous glutamatergic mEPSCs in a subset of cholinergic DBB neurons via activation of non- $\alpha 7 \mathrm{nAChRs,}$ likely the $\alpha 4 \beta 2 \mathrm{nAChR}$ subtype. This $\mathrm{A} \beta_{1-42}$ activation of $\alpha 4 \beta 2$ $\mathrm{nAChRs}$ is in agreement with single-channel recordings from DBB neurons that demonstrated that $\mathrm{A} \beta_{1-42}$ was able to act as an agonist at $\alpha 4 \beta 2 \mathrm{nAChRs}$ in DBB neurons ( $\mathrm{Fu}$ and Jhamandas, $2003)$. Although the actions of $A \beta_{1-42}$ on $n A C h R s$ observed by Fu and Jhamandas (2003) and other authors were at a postsynaptic locus, increasing anatomical and functional evidence suggests that nAChRs are preferentially located at the presynaptic terminals, which regulate neurotransmitter release in the brain (Wonnacott, 1997). However, little is known about the interaction of $\mathrm{A} \beta$ with presynaptic nAChRs. A study performed in synaptosomes showed that low concentrations of $A \beta$ are capable of evoking a sustained increase in presynaptic $\mathrm{Ca}{ }^{2+}$ via activation of both non- $\alpha 7$ and $\alpha 7$ nAChRs (Dougherty et al., 2003). Thus, the present electrophysiological study is the first to report $\mathrm{A} \beta$ modulation of synaptic transmission through nAChRs at a presynaptic level.

Studies performed in a variety of brain regions have demonstrated that activation of nAChRs can modulate presynaptic glutamate-mediated synaptic transmission or glutamate release via either $\alpha 7$ or $\alpha 4 \beta 2$ nAChRs (Vidal and Changeux, 1993; McGehee et al., 1995; Alkondon et al., 1996; Radcliffe and Dani, 1998; Lambe et al., 2003; Rousseau et al., 2005). In keeping with such studies, we have observed that in most basal forebrain cholinergic neurons, nicotine-induced activation of nAChRs was able to increase, in a dose-dependent manner, the frequency of spontaneous mEPSCs (data not shown). The increase in mEPSC frequency evoked by nicotine without any change in peak amplitude or other kinetic parameters of mEPSC is a similar effect to that which we report for $\mathrm{A} \beta_{1-42}$ in the present study and consistent with a presynaptic locus of action.

In another subset of cholinergic neurons, $\mathrm{A} \beta_{1-42}$ was shown to mediate a decrease in the frequency of spontaneous glutamatergic mEPSCs without any significant change in amplitude or kinetic parameters of mEPSCs. This response was not affected by $\mathrm{nAChR}$ antagonists but rather is antagonized by the nonselective group I/II mGluR antagonist MCPG. Thus, the present data support a novel notion that an $\mathrm{A} \beta_{1-42}$-mediated decrease in mEPSC in the cholinergic basal forebrain occurs via an activation of presynaptic mGluRs. At a number of excitatory synapses in the CNS, activation of group II/III mGluRs has been shown to suppress glutamate release (Anwyl, 1999). Indeed, we have previously reported that in the DBB, electrical stimulus-evoked glutamate EPSCs can be suppressed by applications of an mGluR agonist and that the locus of such an effect is presynaptic (Easaw and Jhamandas, 1994). However, less is known concerning potential interactions of $\mathrm{A} \beta_{1-42}$ with mGluRs. $\mathrm{A} \beta_{1-42}$ has been shown to cause membrane depolarization in human hNT neuronal cells and PC12 cells via activation of mGluRs in keeping with a direct postsynaptic effect (Blanchard, 2002). Most data support the view that group II mGluRs are localized to preterminal axons of glutamate neurons, whereas group III mGluRs are primarily present postsynaptically (Schoepp, 2001). In addition, an $\mathrm{A} \beta_{1-}$ 42-mediated decrease in $\mathrm{mEPSC}$ was found to be antagonized by MCPG (a nonselective group I/II mGluR antagonist) in our experiments. Therefore, we postulate that the $\mathrm{A} \beta_{1-42}$-mediated decrease in mEPSC in DBB likely involves an activation of presynaptic mGluRs of group II type. Three possible mechanisms have been proposed to account for the mGluR-mediated inhibition of excitatory transmitter release: suppression of a presynaptic $\mathrm{Ca}^{2+}$ conductance, activation of presynaptic $\mathrm{K}^{+}$channels, or direct inhibition via transmitter release proteins (Anwyl, 1999). Interestingly, $\mathrm{A} \beta$ has been shown to depress evoked excitatory synaptic transmission via modulation of presynaptic L-type calcium channels in rat basolateral amygdala (Ashenafi et al., 2005). This report of $A \beta$-induced suppression of glutamate transmission was shown to be independent of $\alpha 7 \mathrm{nAChR}$ activation, an observation that is consistent with our findings. However, these authors did not test whether activation of mGluRs are involved in the $\mathrm{A} \beta$ modulation of L-type calcium channels and consequently in the suppression of glutamate-mediated neurotransmission.

\section{Functional implications}

This study demonstrates that soluble $\mathrm{A} \beta_{1-42}$ is capable of modulating synaptic transmission via $\alpha 4 \beta 2 \mathrm{nAChRs}$ in septo-hippocampal neurons of the basal forebrain, an important pathway for learning and memory. Thus, the implications of this research are threefold. First, this study suggests that modulation of synaptic transmission by soluble forms of $\mathrm{A} \beta_{1-42}$ may be a potential pathological mechanism for the cognitive decline observed early on in $\mathrm{AD}$. $\mathrm{A} \beta_{1-42}$ augmentation of glutamate neurotransmission could lead to deleterious effects over the long term, whereas $\mathrm{A} \beta_{1-42}$ reduction in glutamate neurotransmission would weaken cholinergic tone and lead to impaired cognition. Second, the nAChR system could serve as a potential avenue for the treatment of $\mathrm{AD}$. In fact, of the current crop of acetylcholinesterase inhibitors routinely used in the treatment of mild to moderate $\mathrm{AD}$, one agent (galantamine) has been identified to have activity at the nicotinic receptors in the brain (Smulders et al., 2005). Finally, because the depressant effects of $A \beta_{1-42}$ on cholinergic cells are expressed through presynaptic mGluRs, the latter receptors may represent novel therapeutic targets for $\mathrm{AD}$ therapies. 


\section{References}

Alkondon M, Rocha ES, Maelicke A, Albuquerque EX (1996) Diversity of nicotinic acetylcholine receptors in rat brain. $\alpha$-Bungarotoxin-sensitive nicotinic receptors in olfactory bulb neurons and presynaptic modulation of glutamate release. J Pharmacol Exp Ther 278:1460-1471.

Anwyl R (1999) Metabotropic glutamate receptors: electrophysiological properties and role in plasticity. Brain Res Brain Res Rev 29:83-120.

Ashenafi S, Fuente A, Criado JM, Riolobos AS, Heredia M, Yajeya J (2005) Beta-amyloid peptides25-35 depresses excitatory synaptic transmission in the rat basolateral amygdala "in vitro." Neurobiol Aging 26:419-428.

Blanchard BJ, Thomas VL, Ingram VM (2002) Related mechanism of membrane depolarization caused by the Alzheimer Abeta1-42 peptide. Biochem Biophys Res Commun 293:1197-1203.

Clements JD, Bekkers JM (1997) Detection of spontaneous synaptic events with an optimally scaled template. Biophys J 73:220-229.

Davies CA, Mann DM, Sumpter PQ, Yates PO (1987) A quantitative morphometric analysis of the neuronal and synaptic content of the frontal and temporal cortex in patients with Alzheimer's disease. J Neurol Sci 78:151-164.

Dineley KT, Bell KA, Bui D, Sweatt JD (2002) Beta-amyloid peptide activates alpha 7 nicotinic acetylcholine receptors expressed in Xenopus oocytes. J Biol Chem 277:25056-25061.

Dougherty JJ, Wu J, Nichols RA (2003) Beta-amyloid regulation of presynaptic nicotinic receptors in rat hippocampus and neocortex. J Neurosci 23:6740-6747.

Easaw JC, Jhamandas JH (1994) Presynaptic modulation of glutamatergic neurotransmission by $\mathrm{GABA}_{\mathrm{B}}$ and metabotropic receptors in the horizontal limb of the diagonal band of Broca (hDBB) in vitro. Soc Neurosci Abstr 20:1119.

Easaw JC, Petrov T, Jhamandas JH (1997) An electrophysiological study of neurons in the horizontal limb of the diagonal band of Broca. Am J Physiol 272:C163-C172.

Eckenstein F, Sofroniew MV (1983) Identification of central cholinergic neurons containing both choline acetyltransferase and acetylcholinesterase and of central neurons containing only acetylcholinesterase. J Neurosci 3:2286-2291.

Frazier CJ, Buhler AV, Weiner JL, Dunwiddie TV (1998) Synaptic potentials mediated via $\alpha$-bungarotoxin-sensitive nicotinic acetylcholine receptors in rat hippocampal interneurons. J Neurosci 18:8228-8235.

Fu W, Jhamandas JH (2003) Beta-amyloid peptide activates non-alpha7 nicotinic acetylcholine receptors in rat basal forebrain neurons. J Neurophysiol 90:3130-3136.

Hamos JE, Degennaro LJ, Drachman DA (1989) Synaptic loss in Alzheimer's disease and other dementias. Neurology 39:355-361.

Hartig W, Seeger J, Naumann T, Brauer K, Bruckner G (1998) Selective in vivo fluorescence labelling of cholinergic neurons containing p75(NTR) in the rat basal forebrain. Brain Res 808:155-165.

Jhamandas JH, Bourque CW (2000) Amyloid $\beta$-protein $(\mathrm{A} \beta)$ affects the excitability of rat basal forebrain neurons in an in vitro brain explant preparation. Soc Neurosci Abstr 26:2392.

Lamb PW, Melton MA, Yakel JL (2005) Inhibition of neuronal nicotinic acetylcholine receptor channels expressed in Xenopus oocytes by betaamyloid 1-42 peptide. J Mol Neurosci 27:13-21.

Lambe EK, Picciotto MR, Aghajanian GK (2003) Nicotine induces glutamate release from thalamocortical terminals in prefrontal cortex. Neuropsychopharmacology 28:216-225.

Lambert MP, Barlow AK, Chromy BA, Edwards C, Freed R, Liosatos M, Morgan TE, Rozovsky I, Trommer B, Viola KL, Wals P, Zhang C, Finch CE, Krafft GA, Klein WL (1998) Diffusible, nonfibrillar ligands derived from Abeta1-42 are potent central nervous system neurotoxins. Proc Natl Acad Sci USA 95:6448-6453.

Larson J, Lynch G, Games D, Seubert P (1999) Alternations in synaptic transmission and long-term potentiation in hippocampal slices from young and aged PDAPP mince. Brain Res 840:23-35.

Masliah E, Terry RD, Alford M, Deteresa R, Hansen LA (1991) Cortical and subcortical patterns of synaptophysinlike immunoreactivity in Alzheimer's disease. Am J Pathol 138:235-236.

McGehee DS, Heath MJ, Gelber S, Devay P, Role LW (1995) Nicotine enhancement of fast excitatory synaptic transmission in CNS by presynaptic receptors. Science 269:1692-1696.

McKhann G, Drachman D, Folstein M, Katzman R, Price D, Stadlan EM
(1984) Clinical diagnosis of Alzheimer's disease: report of the NINCDSADRDA Work Group under the auspices of Department of Health and Human Services Task Force on Alzheimer's disease. Neurology 34:939-944.

Mesulam MM, Mufson EJ, Wainer BH, Levey AI (1983) Central cholinergic pathways in the rat: an overview based on an alternative nomenclature (Ch1-Ch6). Neuroscience 10:1185-1201.

Moechars D, Dewachter I, Lorent K, Reverse D, Baekelandt V, Naidu A, Tesseur I, Spittaels K, Haute CV, Checler F, Godaux E, Cordell B, Van Leuven F (1999) Early phenotypic changes in transgenic mice that overexpress different mutants of amyloid precursor protein in brain. J Biol Chem 274:6483-6492.

Momiyama T, Fukazawa Y (2007) $D_{1}$-like dopamine receptors selectively block P/Q-type calcium channels to reduce glutamate release onto cholinergic basal forebrain neurons of immature rats. J Physiol (Lond) 580:103-117.

Pettit DL, Shao Z, Yakel JL (2001) Beta-amyloid (1-42) peptide directly modulates nicotinic receptors in the rat hippocampal slice. J Neurosci 21:RC120(1-5).

Phelan KD, Gallagher JP (1992) Direct muscarinic and nicotinic receptormediated excitation of rat medial vestibular nucleus neurons in vitro. Synapse 10:349-358.

Price DL (1986) New perspectives on Alzheimer's disease. Annu Rev Neurosci 9:489-512.

Radcliffe KA, Dani JA (1998) Nicotinic stimulation produces multiple forms of increased glutamatergic synaptic transmission. J Neurosci 18:7075-7083.

Rousseau SJ, Jones IW, Pullar IA, Wonnacott S (2005) Presynaptic alpha7 and non-alpha7 nicotinic acetylcholine receptors modulate $[3 \mathrm{H}] \mathrm{d}$ aspartate release from rat frontal cortex in vitro. Neuropharmacology 49:59-72.

Schoepp DD (2001) Unveiling the functions of presynaptic metabotropic glutamate receptors in the central nervous system. J Pharmacol Exp Ther 299:12-20.

Selkoe DJ (2002) Alzheimer's disease is a synaptic failure. Science 298:789-791.

Small DH, Mok SS, Bornstein JC (2001) Alzheimer's disease and AP toxicity: from top to bottom. Nat Rev Neurosci 2:595-598.

Smulders CJ, Zwart R, Bermudez I, van Kleef RG, Groot-Kormelink PJ, Vijverberg HP (2005) Cholinergic drugs potentiate human nicotinic alpha4beta2 acetylcholine receptors by a competitive mechanism. Eur J Pharmacol 509:97-108.

Vidal C, Changeux JP (1993) Nicotinic and muscarinic modulations of excitatory synaptic transmission in the rat prefrontal cortex in vitro. Neuroscience 56:23-32.

Walsh DM, Klyubin I, Fadeeva JV, Cullen WK, Anwyl R, Wolfe MS, Rowan MJ, Selkoe DJ (2002) Naturally secreted oligomers of amyloid beta protein potently inhibit hippocampal long-term potentiation in vivo. Nature 416:535-539.

Wang HY, Lee DH, D'Andrea MR, Peterson PA, Shank RP, Reitz AB (2000a) Beta-amyloid(1-42) binds to alpha7 nicotinic acetylcholine receptor with high affinity. Implications for Alzheimer's disease pathology. J Biol Chem 275:5626-5632.

Wang HY, Lee DH, Davis CB, Shank RP (2000b) Amyloid peptide A beta(142 ) binds selectively and with picomolar affinity to alpha 7 nicotinic acetylcholine receptors. J Neurochem 75:1155-1161.

Whitehouse PJ, Price DL, Struble RG, Clark AW, Coyle JT, Delon MR (1982) Alzheimer's disease and senile dementia: loss of neurons in the basal forebrain. Science 215:1237-1239.

Wonnacott S (1997) Presynaptic nicotinic ACh receptors. Trends Neurosci 20:92-98.

Wu J, Kuo YP, George AA, Xu L, Hu J, Lukas RJ (2004) Beta-amyloid directly inhibits human alpha4beta2-nicotinic acetylcholine receptors heterologously expressed in human SH-EP1 cells. J Biol Chem 279:37842-37851.

Wu M, Shanabrough M, Leranth C, Alreja M (2000) Cholinergic excitation of septohippocampal GABA but not cholinergic neurons: implications for learning and memory. J Neurosci 20:3900-3908.

Zhang M, Wang YT, Vyas DM, Neuman RS, Bieger D (1993) Nicotinic cholinoceptor-mediated excitatory postsynaptic potentials in rat nucleus ambiguus. Exp Brain Res 96:83-88. 